\title{
Are post-dispersed seeds of Eucalyptus globulus predated in the introduced range? Evidence from an experiment in Portugal
}

\author{
Ernesto Deus $^{1,2}$, Joaquim S. Silva ${ }^{2,3}$, Hélia Marchante ${ }^{3,1}$, Elizabete Marchante ${ }^{1}$, and Catarina Félix ${ }^{3,2}$ \\ ${ }^{1}$ Centre for Functional Ecology, Department of Life Sciences, University of Coimbra, Calçada Martim de \\ Freitas, 3000-456 Coimbra, Portugal \\ ${ }^{2}$ Centre for Applied Ecology "Prof. Baeta Neves", InBIO Associate Laboratory, School of Agriculture, \\ University of Lisbon, Tapada da Ajuda, 1349-017 Lisbon, Portugal \\ ${ }^{3}$ Coimbra Agriculture School, Polytechnic Institute of Coimbra, Bencanta, 3045-601, Coimbra, Portugal
}

Correspondence: Ernesto Deus (ernestodeus@isa.ulisboa.pt)

Received: 14 August 2017 - Revised: 20 February 2018 - Accepted: 19 March 2018 - Published: 26 April 2018

\begin{abstract}
Plantations of Eucalyptus globulus Labill. have been expanding rapidly worldwide. The species is considered invasive in several regions. While in the native range, post-dispersal seed predation is known to severely limit eucalypt recruitment, there is no experimental evidence of seed predation in the introduced range. We hypothesised that E. globulus seeds largely escape predation in Portugal, which may explain its prolific recruitment in some locations. We tested this hypothesis in central Portugal by exposing E. globulus seeds to the local fauna. For comparison purposes, we also used seeds from locally common species: Acacia dealbata Link (alien, larger, elaiosome-bearing seeds) and Cistus salviifolius L. (native, similarly sized seeds). We installed 30 feeding stations across three study sites, each one dominated by one study species. Each feeding station featured four feeders with different animal-access treatments: invertebrates; vertebrates; full access; no access (control). We placed five seeds of each plant species every day in each feeder and registered the number of seeds missing, eaten and elaiosome detached over 9 summer days.

Eucalyptus globulus seeds were highly attractive to fauna in the three sites. Nearly half of E. globulus seeds were predated or removed, thus contradicting our hypothesis. Surprisingly, E. globulus and A. dealbata seeds were used by animals in similar proportions and $C$. salviifolius seeds were the least preferred. Vertebrates were the predominant seed predators and preferred the alien seeds. Invertebrates used all seed species in similar proportions. We found spatial variation regarding the predominant type of seed predators and the levels of seed predation according to the following patterns: predominance of vertebrates; predominance of invertebrates; negligible seed predator activity. Locations with negligible seed predation were abundant and scattered across the study area. Such spatial variation may help to explain the heterogeneous recruitment patterns of E. globulus seedlings found in previous studies.
\end{abstract}

\section{Introduction}

Eucalyptus globulus Labill. is an evergreen tree native to southern Victoria (Australia), Tasmania and the Bass Strait Islands (Jordan et al., 1994). Plantations of E. globulus have expanded rapidly worldwide since the mid-20th century, becoming one of the most popular exotic plantation trees (Potts, 2004; Rejmánek and Richardson, 2011). On the other hand,
E. globulus is also considered invasive in different world regions (Rejmánek and Richardson, 2013). In Portugal, where E. globulus plantations are widespread, it was found that the recruitment of E. globulus seedlings is several times higher than in the native range (Catry et al., 2015; Águas et al., 2017; Deus et al., 2016). There has been a comprehensive attempt to understand the prolific recruitment of E. globulus in the introduced range (e.g. Catry et al., 2015; Águas 
et al., 2014; Becerra and Bustamante, 2008; Fernandes et al., 2017; Calviño-Cancela and Rubido-Bará, 2013), but the impact of predators on post-dispersed seeds has been poorly studied.

According to the "enemy release hypothesis", the invasiveness of some alien species may be explained by the scarcity of natural enemies in the introduced range, such as pathogens, parasites and predators (Keane and Crawley, 2002; Mitchell and Power, 2003; Colautti et al., 2004). A high propagule pressure originating from plantations (Rouget and Richardson, 2003; Rejmánek et al., 2005), associated with few seed losses by post-dispersal predation, may help to explain the higher recruitment of E. globulus in the introduced range. Seed-harvesting animals can play a key role in the dynamics of plant populations (Fenner and Thompson, 2005; Chambers and MacMahon, 1994; Hulme, 1998). There are reports of seed-harvesting animals facilitating plant invasions through seed dispersal (Richardson et al., 2000; Gosper et al., 2005; Holmes, 1990), as well as alien plants benefiting from reduced seed predation (Wolfe, 2002; Fenner and Lee, 2001).

In southeast Australia, where E. globulus is native, seedharvesting ants heavily predate the post-dispersed seeds from eucalypts, especially in the summer (Andersen and Ashton, 1985; Ashton, 1979), severely limiting eucalypt recruitment (Wellington and Noble, 1985; Andersen, 1982; Drake, 1981). In the native range, eucalypt recruitment is strongly enhanced after wildfires, following a massive, synchronised fire-triggered seed dehiscence that satiates seed-harvesting ants and provides a post-fire seed bed free from competition (Ashton, 1979; Janzen, 1969; Andersen, 1989; O’Dowd and Gill, 1984). To our knowledge, there is no experimental evidence of predation of post-dispersed eucalypt seeds in the introduced range. In NW Spain, in a preliminary experiment, Calviño-Cancela and Rubido-Bará (2013) did not find any evidence of predation of post-dispersed E. globulus seeds. There are only anecdotal reports of animals predating encapsulated eucalypt seeds outside the native range, particularly birds (Calviño-Cancela, 2013; Bean and Russo, 1986) and squirrels (Jacobs, 1979).

In order to investigate seed predation, it is common practice to use seed removal experiments (e.g. Holmes, 1990; Wandrag et al., 2013; Montesinos et al., 2012). In these experiments, a known amount of seeds are made available to animals, and the number of seeds removed is registered systematically. Many studies distinguish among types of animals, particularly vertebrates and invertebrates, using animal-exclusion treatments (e.g. Alba-Lynn and Henk, 2010; Auld and Denham, 1999), because vertebrates and invertebrates may use different foraging areas (Hulme, 1997; Alba-Lynn and Henk, 2010), and the fate of the seeds may depend on the type of harvesting animals (Fedriani et al., 2004; Alba-Lynn and Henk, 2010; Holmes, 1990). Some studies also expose the studied seeds to different habitats and micro-habitats, targeting different animal populations that may have different foraging habits and food preferences (Meiss et al., 2010; Barberá et al., 2006; Ordóñez and Retana, 2004).

The present study is based on a seed removal experiment, conducted in central Portugal, designed to answer a core research question related to the invasiveness of a widespread timber species: do animals play a relevant role in the fate of post-dispersed $E$. globulus seeds in the introduced range? Seeds from two other locally common species, Acacia dealbata Link (alien, larger, elaiosome-bearing seeds) and Cistus salviifolius L. (native, similarly sized seeds), were included in the experiment for comparison purposes. The specific objectives of this experiment were (a) to investigate the occurrence of predation of E. globulus seeds; (b) to explore spatial variation throughout the study area regarding the activity of different types of seed predators and seed preferences; (c) to compare the relative importance of vertebrates and invertebrates as seed predators and their preferences between the three seed species. We had the following expectations: E. globulus seeds will largely escape predation, in contrast to the native range; some locations will be more intensely foraged than others, either by invertebrates or by vertebrates; E. globulus seeds will be the least preferred seeds, as they are exotic, unlike $C$. salviifolius, and lack an ant-attractive elaiosome, unlike $A$. dealbata seeds.

\section{Materials and methods}

\subsection{Study species}

Eucalyptus globulus (Myrtaceae) is an evergreen tree that grows up to $55 \mathrm{~m}$ tall. Seeds are enclosed in woody pseudocapsules, with narrow valves that open to release the seeds following capsule desiccation (Silva et al., 2016; Suitor, 2008). Seed shed occurs throughout the year, but a massive seed shed is triggered by wildfires (Santos et al., 2015; Cremer, 1965). Seeds are very small (maximum width ranging from ca. 1 to $2 \mathrm{~mm}$ ), non-dormant, short-lived and do not form a durable soil seed bank (Santos et al., 2015; López et al., 2000).

Acacia dealbata (Fabaceae) is an evergreen tree, up to $15 \mathrm{~m}$, native to Australia and eastern Tasmania, regarded as an aggressive invader in Portugal and elsewhere (Lorenzo et al., 2010; Rejmánek and Richardson, 2013). The fruits are pods which mature annually and release their seeds from June to August (in the Northern Hemisphere). Seeds are ca. 4-5 $\times 2.5 \mathrm{~mm}$, hard-coated, dormant, forming persistent soil seed banks and possess a lipid-rich elaiosome, nearly half the size of the seed.

Cistus salviifolius (Cistaceae) is a shrub, up to $90 \mathrm{~cm}$, occurring spontaneously throughout the Mediterranean Basin (Moreira et al., 2012). The fruits are capsules, generally mature annually in early summer, and may take several months until all seeds are released (Bastida and Talavera, 2002). Seeds are numerous, very small (ca. $1 \mathrm{~mm}$ ), hard-coated, 
have an endosperm and are dormant, accumulating in persistent soil seed banks (Bastida and Talavera, 2002; Thanos and Georghiou, 1988).

Seeds from $A$. dealbata and $C$. salviifolius were included in the experiment for the following reasons: both species occur in the study area; elaiosome-bearing seeds of $A$. dealbata are harvested by ants in this region (Montesinos et al., 2012) and, being highly attractive to seed-harvesting animals, should confirm their presence, particularly that of ants (Brew et al., 1989; Wandrag et al., 2013; Hughes et al., 1994); seeds from $C$. salviifolius have a similar size to E. globulus and are also known to be harvested by native ants (Bastida et al., 2009).

\subsection{Study area}

The experiment was undertaken in a peri-urban area of Coimbra, in the central west of Portugal $\left(40^{\circ} 12^{\prime} 25^{\prime \prime} \mathrm{N}\right.$; $8^{\circ} 27^{\prime} 01^{\prime \prime} \mathrm{W}$ ), including the campus of the Coimbra Agriculture School (ESAC) and a nearby area (map in Supplement S1; Fig. S1). The climate is Mediterranean with Atlantic influence, with mean annual precipitation of $922 \mathrm{~mm}$ and mean monthly temperatures between $21.9^{\circ} \mathrm{C}$ in July/August and $9.9^{\circ} \mathrm{C}$ in January (period 1981-2010; IPMA, 2014). Altitude ranges between 30 and $90 \mathrm{~m}$. It comprises a mosaic of land uses, including agricultural land and forest, with scattered roads, tracks and buildings. Sampling units were selected in study sites with distinct structure and composition of the vegetation. We did not aim to test habitat effect (no replications for habitat), but simply to expose the study seed species, especially E. globulus seeds, to potentially distinct fauna. Since local fauna should be more adapted to use seeds of local plant species as a food resource, we chose three sites, each one dominated by one of the three plant species under study.

Site characterisation was made through a visual estimate of different variables within a $5 \mathrm{~m}$ radius from the centroid of each sampling unit (10 in each site). In each of these areas, we identified all plant species with cover greater than $5 \%$ (including canopy cover). The first site was an E. globulus plantation with a total area of $0.76 \mathrm{ha}$, an average tree height of $13.8 \mathrm{~m}(\mathrm{SD}=3.2)$ and an average canopy cover of $62 \%(\mathrm{SD}=11.2)$. Besides eucalypts, measuring around $15 \mathrm{~m}$ height, there were a few trees of other species (Quercus suber L.; Quercus robur L.; Fraxinus angustifolia Vahl). The E. globulus plantation had a shrub cover of $57.5 \%$ $(\mathrm{SD}=14.9 \%)$ and featured the highest species richness, including $Q$. suber, Q. robur, Q. coutinhoi, Vinca difformis Pourr., Ulmus sp., Rubus sp., Hedera helix L., among others (ordered by decreasing importance). The second and the largest site (1.9 ha) was a native oak stand, with an average tree height of $6.9 \mathrm{~m}(\mathrm{SD}=3.4)$ and featuring the lowest canopy cover $(41.0 \%$; $\mathrm{SD}=26.9)$. Most frequent trees were $Q$. suber, $Q$. robur and Arbutus unedo L. The oak stand featured the highest shrub cover $(63.5 \%$; SD $=20.6)$, even though this rate must be inflated due to the presence of C. salviifolius thickets in the sampling units. The third site was a small area ( 0.32 ha) invaded by $A$. dealbata, featuring the highest canopy cover $(86.9 \% ; \mathrm{SD}=7.5 ;$ A. dealbata exclusively) and the lowest shrub cover $(31 \%$; SD $=10.4)$, mostly composed of $A$. dealbata recruits and a few, sparse Rubus sp.

\subsection{Experimental design and data collection}

Five seeds of each study species, totaling 15 seeds, were placed inside feeders - plastic Petri dishes with no lid $(10 \mathrm{~cm}$ diameter and $1 \mathrm{~cm}$ deep). We designed three types of feeders in order to select the type of animals that had access to the seeds. The invertebrate feeder was designed to prevent the access to the seeds by vertebrate animals. It was a Petri dish, placed on the ground, surrounded by a wire mesh cage (mesh size $1 \mathrm{~cm}^{2}$ ). The vertebrate feeder was designed to prevent access by invertebrates, particularly ants and other crawling insects. This feeder was a Petri dish elevated nearly $3 \mathrm{~cm}$ above the soil surface, using one plastic tripod fixed in three plastic screw anchors piercing the ground, and the bottom of the Petri/tripod coated with a sticky substance $\left(\right.$ Tanglefoot ${ }^{\circledR}$ ). A third type of feeder was included to assess the combined influence of both vertebrates and invertebrates, referred to as total access feeder. The total access feeder was a Petri dish placed on the ground, fixed by three nails, with unrestricted access to the seeds. In order to control the influence of external factors, such as seed fall from neighbouring plants or seed removal by wind or rain, we included a control feeder, designed to prevent any access of seed-harvesting animals to seeds. Each control feeder was made of an invertebrate feeder surrounded by a wire mesh cage (scheme in Supplement S1; Fig. S2). A set of these four feeder types will be referred to as a feeding station, each one corresponding to a sampling unit. Thirty feeding stations were evenly distributed throughout the three study sites (10 feeding stations per site), totaling 120 feeders (30 feeders of each type). Each feeding station was installed adjacent to one reproductive individual of the studied species: around the stem of E. globulus and $A$. dealbata, or adjacent to the canopy of $C$. salviifolius thickets, with a minimum distance of $1 \mathrm{~m}$ between feeders (scheme in Supplement S1; Fig. S3). The minimum distance to the nearest feeding stations was $10 \mathrm{~m}$, in order to minimise the influence (animal and seed rain) between neighbouring feeding stations. Ten metres were considered adequate, taking into account the size of the three sites.

All feeders, including the control feeders, were emptied every day and replenished between 09:00 and 11:00 UTC+1 with another set of five seeds of each of the studied species. Overall, each day, 600 seeds of each seed species were placed in the feeders $(5$ seeds $\times 4$ feeder types $\times 30$ feeding stations), totaling 5400 seeds during the 9 days of the experiment. Feeders were monitored daily for 10 consecutive days in July 2014. Due to rain on the 10th day that caused the loss 
of most seeds from the control feeders, the results from this day were discarded. The duration of the experiment was standard for this kind of assessment, following criteria adopted by other studies (e.g. Alba-Lynn and Henk, 2010; Harris and Standish, 2008; Hulme, 1997; Andersen, 1982; Montesinos et al., 2012), and was considered adequate given the season and the type of animal agents expected to harvest the seeds. Each day, the following data were recorded for each feeder and seed species: (a) number of seeds removed (denoted "missing"; seeds harvested/transported or eaten leaving no visible evidence; unknown seed fate); (b) number of seeds eaten on-site (denoted "eaten"; confirmed by visible remains of the seeds in the feeder); (c) number of $A$. dealbata seeds missing the elaiosome (denoted "elaiosome"; elaiosome detached or consumed; the seed remains apparently viable in the feeder).

Fresh seeds were used every day in order to assure that all seeds had equal chances of being removed by animals. Seeds were selected randomly, with no size criteria. All A. dealbata seeds had an attached elaiosome. Seeds were handled individually, using tweezers to place them in the feeders. A quick visual inspection of the colour and integrity of the seed and a small pressure applied with the tweezers were enough to ensure that seeds were apparently viable. We discarded all seeds that were soft or hollow, discoloured or apparently damaged. Eucalyptus globulus seeds were provided by Altri, a pulp company, and collected in September 2013 from a seed orchard. Seeds were stored in cool conditions until the beginning of the experiment. Acacia dealbata seeds were collected in nearby areas 1 year before the experiment and stored at room temperature. Cistus salviifolius seeds were collected in the study area in November 2013 and stored at room temperature.

\subsection{Animal identification}

A few days after the seed removal experiment, under similar meteorological conditions, we tried to identify some of the animal species using the seeds. This task was done afterwards to avoid further disturbance of the feeding stations during the experiment. In order to identify invertebrates, particularly ants, known to be the main seed-harvesters of the studied species, we placed one total access feeder with five of each seed species at eight locations showing the highest activity by invertebrates: four locations in the A. dealbata stand, three in the E. globulus plantation and one in the oak stand. Over 2 consecutive days, feeders were monitored regularly between 09:00 and 18:00 UTC +1 by two teams searching for activity inside the feeders. Once activity was detected, the feeder was replenished with the original amount of seeds and monitored for $30 \mathrm{~min}$. The ants that were found using the seeds were collected for identification and the type of action on the seeds (missing, eaten, elaiosome detached) was registered for each ant collected and for each seed species. In the locations where ants were active but not using the seeds, we collected and identified those ants crossing the feeder (apparently showing no interest in the seeds).

In our attempt to identify vertebrates, we focused on rodents, because we had found frequent evidence of rodent activity inside or next to the feeders (faeces; seed remains resulting from nibbling). In order to obtain proof of rodents using the seeds we used camera traps. Camera traps were placed only in the E. globulus plantation where they were more concealed in order to prevent damage or stealing. We chose the six locations in the E. globulus plantation where most activity by vertebrates was registered. In each location, we installed three vertebrate feeders, each containing five seeds from one of the three studied species. In this way, the video footage allowed to show the action of animals with each seed species individually. In each location, camera traps were left for one day, from 17:00 to 10:00 UTC+1 the following day. This period was chosen for the safety of the equipment and allowed covering a few hours of daylight in the late afternoon and morning, and covering the entire night, although this meant that other vertebrate animals may have escaped identification.

\subsection{Data analysis}

In order to explore the spatial variation throughout the study area regarding the activity of different seed predators and seed preferences, we performed a principal component analysis (PCA). The values of the PCA matrix were the proportions of seeds used (missing; eaten; elaiosome) in relation to the total number of available seeds of each species ( 9 days $\times 5$ seeds per day $=45$ seeds), for each combination feeder type $\times$ seed species $(3$ feeders $\times 3$ seed spp. $=9$ variables). Therefore, the PCA was developed using a $30 \times 9$ (feeding stations/variables) matrix. A biplot was built based on the PCA results, aiming at detecting clusters of stations sharing similar patterns of seed predator activity and preferred seeds. These patterns were inferred based on the proportions of seeds used for each combination feeder type $\times$ seed species. We built a map of the study area to assess the distribution of the feeding stations according to the clusters they belong to.

We modelled the effect of explanatory variables: feeder type (three levels: invertebrate, vertebrate and total access feeders), seed species (three levels: E. globulus, A. dealbata and $C$. salviifolius) and their interaction, on the proportion of seeds used (out of 45 seeds available over the 9 days; $n=3$ feeders $\times 3$ seed spp. $\times 3$ sites $\times 10$ stations $=270$ ) using generalised linear mixed models (GLMMs) with a binomial error distribution, following the procedures described in Zuur et al. (2009). Study site (eucalypt plantation, acacia stand and oak stand) and feeding station (10 stations in each site) were included in the model as nested random effects using function glmmPQL of the R package MASS (Venables and Ripley, 2002). This function fits a GLMM model with multivariate normal random effects, using the 
penalised quasi-likelihood approach (Venables and Ripley, 2002). Model fit was assessed by the marginal $R^{2}$ (variance that is explained by the fixed terms of the model), using the R package MuMIn (Bartoń, 2018), according to Nakagawa and Schielzeth (2013). Post hoc pairwise comparisons between all combinations of significant factor levels were performed through Tukey tests with adjusted $p$ values using the $\mathrm{R}$ package multcomp (Hothorn et al., 2008).

In the second stage, we used a similar procedure to model the proportion of seeds used separately for each seed species, but using feeder type, type of animal action on the seeds (missing, eaten, elaiosome detached) and the interaction between the two factors, as explanatory variables. Therefore, four models were produced (one general and one for each studied species) and the corresponding multiple comparisons.

We undertook additional analysis aimed at assessing the potential of seed depletion of each seed species by recording only the occasions (observations) when any seed was used (missing, eaten, elaiosome detached), i.e. occasions when we know that animals found the seeds and could reveal their preferences. Therefore, for each feeder type and seed species, we computed the frequencies of occasions (animal visits) where no (0), some (1-4) and all (5) seeds were either eaten or missing. Elaiosome detachment on A. dealbata seeds was not counted as depletion, since the seeds remain apparently viable in the feeder. The maximum number of occasions (visits by animals) for each seed species in each feeder type would be 270 ( 30 feeders of certain type $\times 9$ days). Using these frequencies, we produced contingency tables for invertebrate, vertebrate and total access feeders, and tested, for each one, the independence between seed species and intensity of seed depletion using $\chi^{2}$ tests. All statistical analyses were performed using $\mathrm{R}$ software (R Core Team, 2017).

\section{Results}

\subsection{Seed predators and seed preferences}

Only 27 out of 4050 seeds $(0.7 \%)$ were missing from the control feeders and only two extra seeds from $C$. salviifolius were found inside a feeder. Therefore, we assumed that there was no relevant interference of external agents on seed removal. A total of 2866 seeds, out of 12150 available $(23.6 \%)$, were used by animals (missing, eaten, elaiosome detached) during the experiment, including 1164 from E. globulus, 1192 from A. dealbata and 510 from C. salviifolius. The day with the lowest number of seeds used was the first day, with 101 out of 1350 seeds $(7.5 \%)$. The number of seeds used increased daily over the experiment until the seventh day, when a maximum was reached (484 seeds; $35.9 \%$ ), practically stabilising afterwards. This temporal dynamic was similar for all seed species and feeder types, but not for the three study sites, since the daily total of seeds used
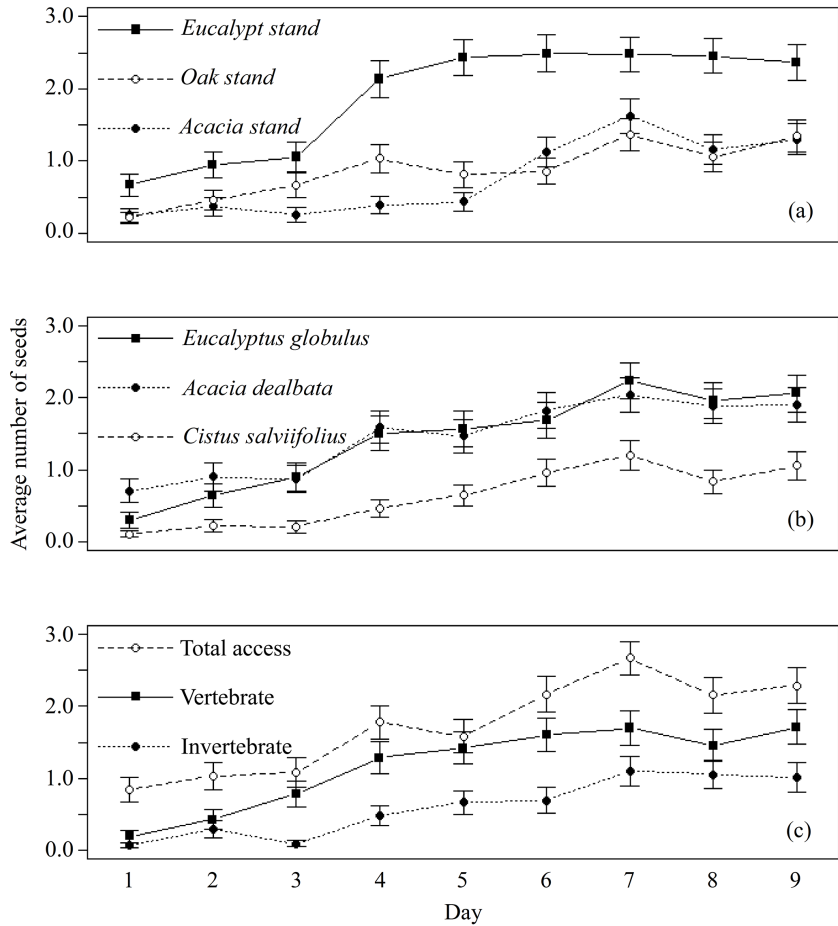

Figure 1. Average daily number of seeds used (missing, eaten, elaiosome detached) per feeder $( \pm \mathrm{SE})$, from a total of five seeds. Data pooled for each day by (a) study site, (b) seed species and (c) feeder type.

stabilised around the fourth day in the E. globulus plantation (Fig. 1).

The first two components of the PCA explained $83 \%$ of the variance. The analysis of the biplot allowed distinguishing three clusters of feeding stations, characterised according to both the rate of seed use by animals and the predominant animal group (vertebrates; invertebrates), regardless of the seed species (Fig. 2). One first cluster of 13 stations (green cluster) shows areas with reduced or negligible seed predation ( $\leq 15 \%$ of seeds used), distributed mainly across A. dealbata and C. salviifolius stands. A second cluster (orange cluster) comprises 11 stations where vertebrate activity was predominant: eight located in E. globulus plantation and three in $C$. salviifolius stand. The third cluster (blue cluster) comprises six stations with mostly invertebrate activity: four in A. dealbata stand, one in E. globulus plantation and one in C. salviifolius stand (Fig. 3).

The general GLMM explained $27 \%$ of variance. The coefficients of the fixed model terms, feeder type, seed species and their interaction were all significant (model description in Supplement S2). Pairwise comparisons showed that seeds from E. globulus and A. dealbata were used in similar proportions in total access, vertebrate and invertebrate feeders. Seeds from C. salviifolius seeds were less used than the alien seeds in the total access feeders and the vertebrate feeders ( $p<0.01$ for both comparisons), but not in the invertebrate 


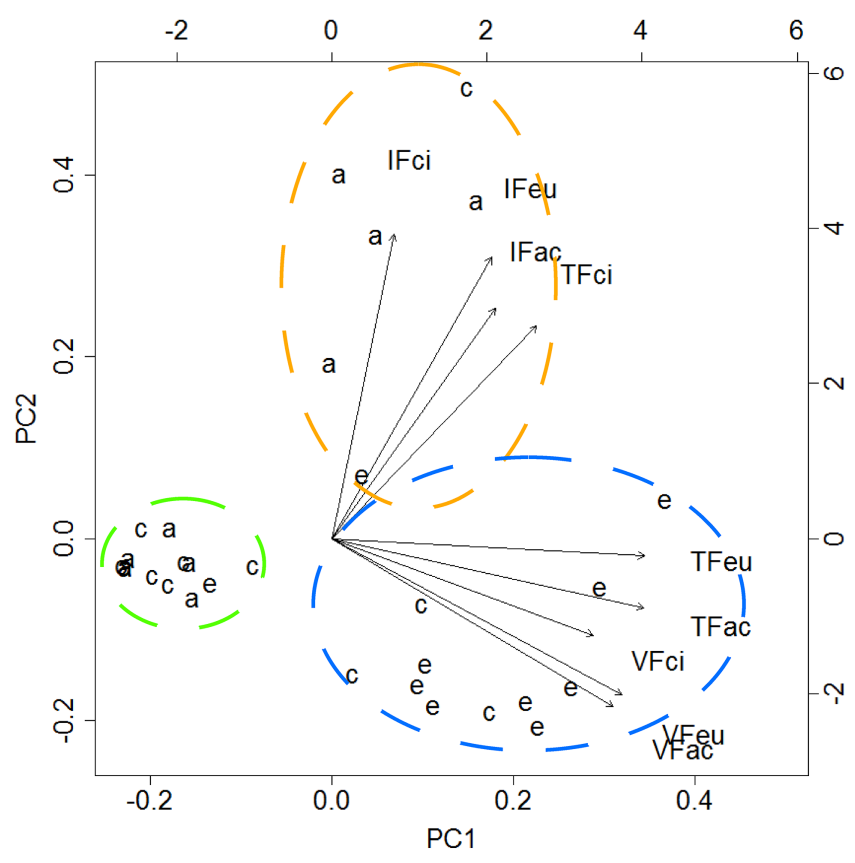

Figure 2. Biplot resulting from the PCA. Dashed circles enclose clusters of feeding stations according to the following patterns: negligible seed predation (green circle); predominance of invertebrates (orange); predominance of vertebrates (blue). Letters a, c and e represent the feeding stations located respectively in the A. dealbata stand, the oak stand and the E. globulus plantations. Each group of four letters represents a variable, composed by the feeder type (IF: invertebrate; VF: vertebrate; TF: total access feeder) and the seed species (ac: A. dealbata; ci: C. salviifolius; eu: E. globulus).

feeders. Alien seeds were used in greater proportions in vertebrate feeders than in invertebrate feeders $(p=0.03$ and $p<0.01$ respectively). No differences among feeders were found for C. salviifolius (Fig. 4).

The GLMM for E. globulus seeds explained $48 \%$ of variance with feeder type, type of action on the seed (missing, eaten, elaiosome detached) and the interaction between these two variables presenting significant model coefficients. The proportion of eaten seeds was significantly lower than the proportion of missing seeds in total access feeders and invertebrate feeders ( $p<0.01$ for both comparisons) but not in vertebrate feeders. The proportion of eaten seeds was much lower in the invertebrate feeders than in total access feeders and vertebrate feeders $(p<0.01$ for both comparisons; Fig. 5).

The GLMM for A. dealbata seeds explained $65 \%$ of variance with both variables and their interaction showing significant coefficients. The proportion of missing seeds was significantly higher in total access feeders and vertebrate feeders than in invertebrate feeders $(p<0.01$ for both comparisons). In invertebrate feeders, no differences were found between missing, eaten and with elaiosome-detached seeds (Fig. 5).

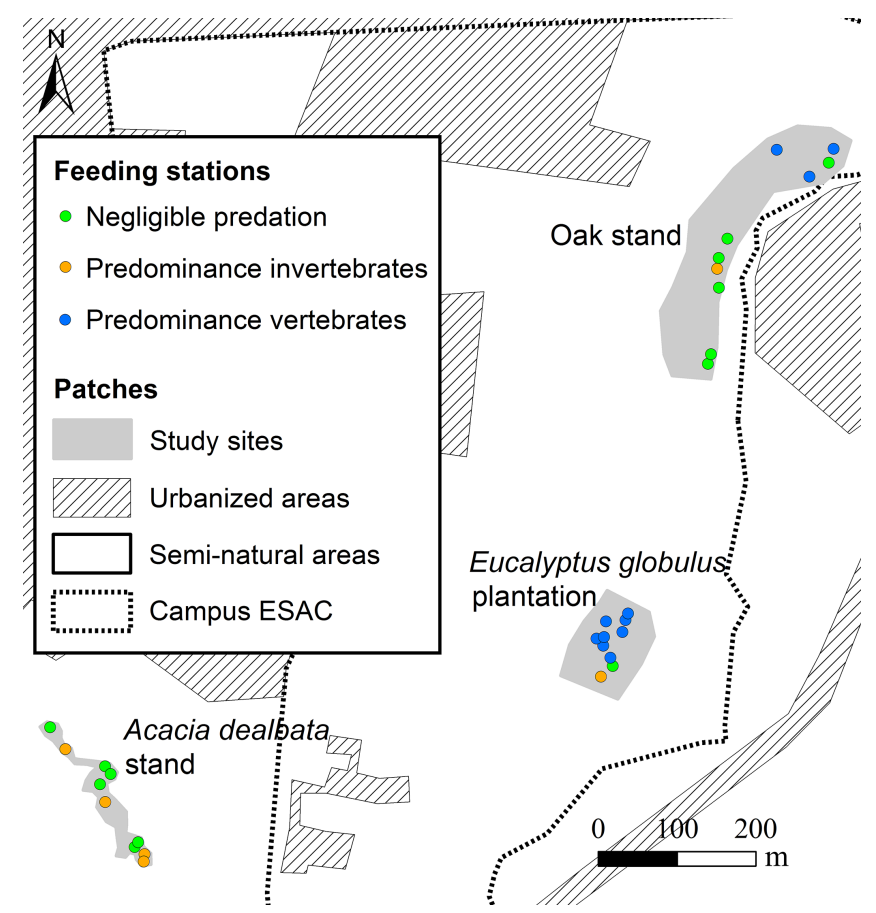

Figure 3. Location of the feeding stations according to shared patterns regarding the predominant seed predators and the level of seed predation.

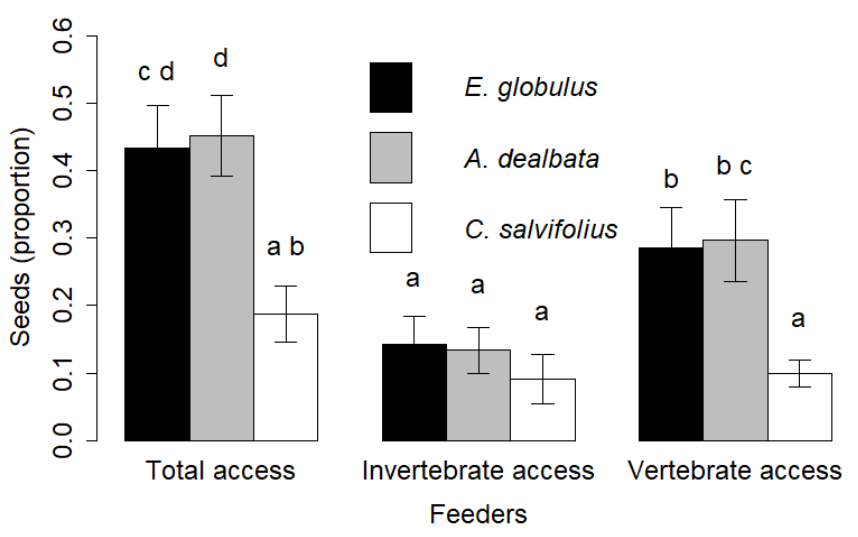

Figure 4. Proportion of seeds used (missing, eaten, elaiosome detached) according to the seed species and feeder type. Different letters above the bars indicate significant differences (post hoc pairwise Tukey tests).

The GLMM for C. salviifolius seeds explained $74 \%$ of variance with both variables being significant, but not their interaction, which was therefore removed from the final model. The proportion of eaten seeds was significantly lower than the proportion of seeds missing in total access feeders and vertebrate feeders ( $p<0.01$ for both comparisons), and was absent from invertebrate feeders (Fig. 5).

The frequencies of occasions (animal visits) where no (0), some (1-4) or all (5) seeds were eaten or missing were signif- 


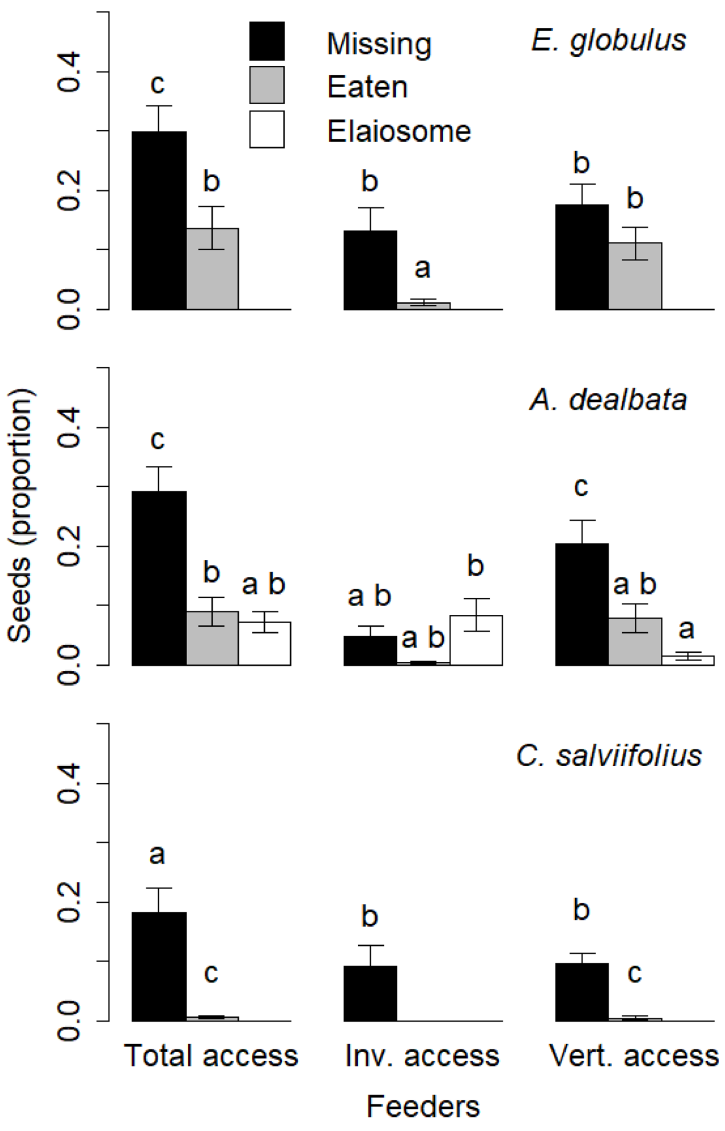

Figure 5. Proportion of seeds used according to the seed species, feeder type and the type of action on the seed (missing, eaten, elaiosome detached). Different letters above the bars indicate significant differences (post hoc pairwise Tukey tests).
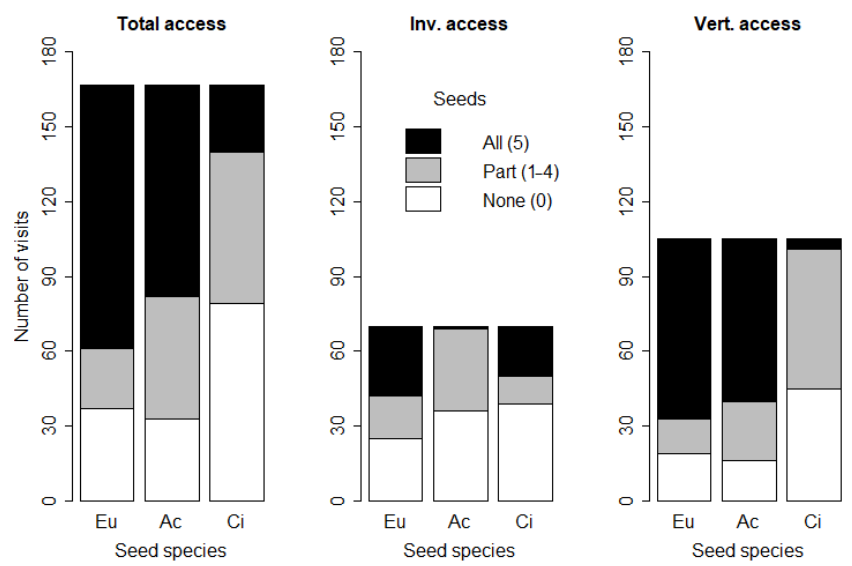

Figure 6. Number of animal visits (any seed used on a given day: missing, eaten, elaiosome detached) where no (0), some (1-4) or all (5) seeds were missing or eaten, according to the feeder type and seed species. Eu: Eucalyptus globulus; Ac: Acacia dealbata; Ci: Cistus salviifolius. icantly related with the seed species ( $p<0.01$ for all feeders). Total access feeders registered the greater number of occasions when any seed was used (missing, eaten, elaiosome detached) by animals (167 out of 270 opportunities; $61.9 \%)$. In total access feeders, E. globulus seeds had the highest proportion of occasions when all five seeds were eaten or missing $(63.5 \%)$ and the lowest proportion of occasions when part of the seeds (1-4 seeds) were missing or eaten $(8.9 \%)$. Invertebrate feeders had the lowest number of occasions when any of the studied seeds were used (70 out of 270 times; $25.9 \%$ ). In the invertebrate feeders, all five A. dealbata seeds were missing or eaten only on one occasion (1.4\%), whereas C. salviifolius and E. globulus were completely depleted (missing or eaten) in more occasions (28.6 and $40.0 \%$ respectively). Moreover, E. globulus seeds registered the lowest proportion of occasions with no seeds missing or eaten $(35.7 \%)$. In vertebrate feeders, there were 105 occasions when any seed was used by animals: $C$. salviifolius seeds registered the lowest frequency of all five seeds missing or eaten $(3.8 \%)$ and the highest proportion of zero seeds missing or eaten (42.9\%). Acacia dealbata and E. globulus seeds had all five seeds missing or eaten in 61.9 and $68.6 \%$ of occasions respectively (Fig. 6).

\subsection{Identified animals}

Four ant species were observed using the seeds in different locations. Individuals from Pheidole sp., observed in one station in the A. dealbata stand, transported seeds of the three species. Tetramorium sp., present in two locations in the A. dealbata stand, were observed eating (or perhaps detaching) the elaiosome of $A$. dealbata seeds, and transporting E. globulus and C. salviifolius seeds. Leptothorax affinis was found in one location in the E. globulus plantation and only showed interest in the elaiosome of A. dealbata seeds. Temnothorax sp. was observed in one location in the oak stand transporting A. dealbata and E. globulus seeds. In other locations, other ant species apparently had no interest in any of the seed species, namely Plagiolepis pygmaea in one location in the E. globulus plantation, Linepithema humile in two locations in the E. globulus plantation and Crematogaster scutellaris in one location in the A. dealbata stand.

The camera traps recorded small rodents (Apodemus sylvaticus) in four out of six locations within the E. globulus plantation. Individuals from this species apparently predated seeds of all species. The feeder containing E. globulus seeds was depleted in the four locations, the feeder with A. dealbata seeds was depleted in three locations (apparently one feeder remained unnoticed) and two feeders with $C$. salviifolius seeds were partially depleted (apparently seeds were ignored in two feeders). Seed remains (crushed testa) were consistent with observations from the main experiment. Edited video footage is available in Supplement S3. 


\section{Discussion}

\subsection{Seed predators and seed preferences}

One of the key findings of this study is the experimental demonstration of predation (and removal) of post-dispersed E. globulus seeds in the introduced range, by both vertebrates and invertebrates. The hypothesis that E. globulus seeds largely escape predation was rejected, since nearly half the seeds were rapidly eaten or missing from total access feeders. The rate of seed use from total access feeders is a good indicator because it reflects the combined influence of vertebrates and invertebrates in the study area. The use of E. globulus seeds by animals, together with the other seed species, occurred in the three study sites, suggesting that local fauna rapidly start using newly arrived seeds. However, it is important to note that the other half of E. globulus seeds remained intact. This contrasts with reports of eucalypt seeds in the native range that found near-depletion by seedharvesting ants (Ashton, 1979; Wellington and Noble, 1985; Drake et al., 2009). Nevertheless, like many seed removal experiments, the rates of seed use may be inflated and should be regarded with caution for multiple reasons: the animals may have become accustomed at foraging those locations, as shown by the daily increase of seeds used; any olfactory clue from one of the seed species may have influenced the finding of other seeds; seeds displayed in clumps, and in plain sight, are more easily detected (Andersen and Ashton, 1985; Myster and Pickett, 1993; Hulme, 1994); the experiment was conducted in the summer, when animal activity is higher.

Invertebrates, particularly ants, had less importance in this study, which was unexpected for several reasons. First, in the native range, it is well documented that seeds of both $\mathrm{Eu}$ calyptus (Ashton, 1979; Drake, 1981) and myrmecochorous Acacia seeds (Auld, 1986; Andersen and Ashton, 1985) are highly attractive to ants. However, we must take into account that in Australia, seed-eating rodents are scarce, contrasting with an exceptionally abundant and diverse ant fauna (Morton, 1985), with a profusion of myrmecochory (Berg, 1975; Milewski and Bond, 1982). Second, in the introduced range, ants have been reported as the predominant seed harvesters of myrmecochorous Acacia spp., while rodents have a minor impact (Wandrag et al., 2013; Holmes, 1990). Third, in the region of the present study, ant communities are ubiquitous and relatively diverse (Cammell et al., 1996), and we could only find reports of ants using both A. dealbata (Montesinos et al., 2012) and C. salviifolius seeds (Bastida et al., 2009) in nearby regions. The lesser importance of ants may be explained by the availability of alternative food sources; the disruption of foraging pathways due to the presence of other ants, such as the invasive Linepithema humile (Human and Gordon, 1996), which was observed in some locations where seeds remained intact; the satiation by concurrent dehiscence (Holmes, 1990); and the lower probabil- ity of feeder encounter due to small-scale patchiness of ant foraging (Arnan et al., 2010).

Contrary to our expectations, invertebrates, particularly ants, did not prefer $A$. dealbata seeds. We expected that the elaiosome would attract a wider array of ant species, both granivorous and non-granivorous (Hughes et al., 1994; Clark and King, 2012). Likewise, the native $C$. salviifolius seeds were not preferred, compared to E. globulus seeds. In fact, all seed species were used by invertebrates in similar proportions. It is worth noting that $A$. dealbata seeds were seldom depleted by invertebrates. Instead, many seeds had the elaiosome removed, a procedure normally associated with smaller ants (Auld and Denham, 1999), suggesting that some ants experienced difficulties carrying these seeds. Acacia dealbata seeds remain viable without the elaiosome, even though the chances of being displaced decrease (Montesinos et al., 2012; Wandrag et al., 2013). This finding contrasts with studies reporting a generalised dispersal of myrmecochorous Acacia seeds by ants in the introduced range (Wandrag et al., 2013; Holmes, 1990; Montesinos et al., 2012). On the other hand, E. globulus seeds were depleted from invertebrate feeders on more occasions, while there were fewer occasions of zero seeds eaten or removed. The smaller size and weight of E. globulus seeds, and the soft seed testa that enables an easy meal (Andersen and Ashton, 1985), may have favoured their selection in relation to the larger seeds of A. dealbata and the hard coated seeds of $C$. salviifolius.

In contrast, vertebrates were the main seed predators, removing a considerable amount of E. globulus and A. dealbata seeds. Video footage from camera traps recorded the small native rodent species, Apodemus sylvaticus, removing all seed species. It is possible, however, that other vertebrates such as birds may have escaped our surveillance. Marchante et al. (2010) suggest that, in Portugal, birds (Streptopelia decaocto) may have ingested and successfully dispersed A. longifolia seeds. Birds were also observed feeding on eucalypt seeds in Spain (Calviño-Cancela, 2013) and California (Bean and Russo, 1986). To our knowledge, there is no previous evidence of rodents feeding on Acacia and Cistus seeds in Europe. Some factors may help to explain the predominance of vertebrates, particularly rodents, in this study. First, they are less easily satiated than invertebrates (Hulme, 1998; Abramsky, 1983). This was supported by the depletion of E. globulus and A. dealbata seeds in most occasions when vertebrate feeders were visited, and the video footage obtained showing that a rodent can rapidly deplete all seeds. Second, small rodents may forage the same areas repeatedly by using pathways determined by prior trails (Jamon, 1994), facilitating recurrent visits to same feeders; this may help to explain the association (same cluster) between total access and vertebrate feeders in the PCA biplot, particularly in the case of E. globulus and A. dealbata seeds. Third, vegetation structure and the fact that the feeders were relatively close to each other (minimum distance of $10 \mathrm{~m}$ ) may have enhanced the performance of small rodents in this study. In fact, verte- 
brate activity mostly took place in the E. globulus plantation that, unlike traditional mono-specific plantations of $E$. globulus, contained considerable plant diversity, providing concealment and diverse food sources for small rodents (Meiss et al., 2010; Gill and Marks, 1991). In contrast, vertebrate activity was unnoticed in the mono-specific, understory-free A. dealbata stand, and concentrated in only three neighbouring stations of the oak stand, probably because rodent activity was limited by sparse shrub cover (Benhamou, 1991).

\subsection{Seed fate and implications for E. globulus establishment}

The video footage obtained (Supplement S3) and the crushed seed testa confirm that small rodents predated E. globulus seeds. We found no clues about the fate of most seeds missing from vertebrate feeders. However, to our knowledge, there is no evidence of small rodents hoarding Eucalyptus seeds or similarly sized seeds. There are only anecdotal reports of birds feeding on eucalypt seeds (Bean and Russo, 1986; Calviño-Cancela, 2013), but endozoochory of E. globulus seeds is unlikely due to the thin testa and seed softness. Therefore, seeds missing from vertebrate feeders were likely predated, resulting in considerable seed losses.

In the invertebrate feeders, a few E. globulus seeds were found eaten, including some left as a hollow seed, evidence attributed to feeding by ants in Australia (Ashton, 1979). Field observations suggested that different ant species, such as Pheidole sp., Tetramorium sp. and Temnothorax sp., may have transported E. globulus seeds, thus some of the missing seeds may have been moved to subterranean ant nests, which happens with Eucalyptus seeds in the native range (Ashton, 1979; Wellington and Noble, 1985). Non-myrmecochorous seeds, such as E. globulus seeds, are normally transported to the nest of granivorous ants (Bas et al., 2009; Drake, 1981) and thus most probably eaten (Ashton, 1979). However, successful ant-mediated dispersal may occur: Eucalyptus seeds may be stored by non-harvester ants (Berg, 1975), occasionally at a depth suitable for germination (Andersen and Ashton, 1985); depending on seed and ant traits (Gorb and Gorb, 1999), some seeds may be dropped/dispersed along the way (Arnan et al., 2010; Retana et al., 2004); non-myrmecochorous seeds may be mistakenly rejected and moved into refuse piles outside ant nests (Retana et al., 2004; Levey and Byrne, 1993).

The spatial variation found in the study area regarding the predominant seed predators and the rates of seed use may imply different seed fates depending on the location where they are shed: (a) predation by vertebrates; (b) predation by invertebrates with occasional dispersal events; (c) escaping predation and integration into soil seed banks. Therefore, the spatial variation of seed predation and dispersal by animals may shape the distribution of many plant species (Andersen, 1982; Whelan et al., 1991; Hulme, 1998, 1997; AlbaLynn and Henk, 2010). Several factors beyond the scope of this study may explain this spatial variation, such as habitat and micro-habitat traits (Alba-Lynn and Henk, 2010; Manson and Stiles, 1998; Whelan et al., 1991), predator risk for seed-eating animals (Sivy et al., 2011), season and phenology of plant species (Bastida et al., 2009), seed abundance (Holmes, 1990; O'Dowd and Gill, 1984) and alternative food sources. Locations with reduced or negligible seed predation may be prime areas for seedling establishment, because seeds have greater chances of becoming embedded in the soil or litter, and are less likely to be detected and predated in the future (Andersen and Ashton, 1985; Hulme, 1994; Vander Wall, 1994). Seeds of E. globulus have no dormancy and therefore a few days may be enough for germination (Silva et al., 2016; López et al., 2000).

Our findings encourage further exploration of the role of seed-harvesting animals in the invasiveness of eucalypt species in the introduced range. Probably, throughout the introduced range, animals predate and disperse post-dispersed seeds of other widespread eucalypt species (e.g. Harwood, 2011; Rejmánek and Richardson, 2013), with implications for the demography and the dynamics of the populations. Further research is needed to evaluate the suitability for seedling establishment and survival of the areas where seeds largely escape predation. Also, the seasonal variation of seed predation, observed in the native range (Ashton, 1979; Andersen and Ashton, 1985), is likely to occur in the introduced range, and is worthy of examination since seed dehiscence occurs throughout the year (Calviño-Cancela and Rubido-Bará, 2013; Cremer, 1965). It may also be appropriate to investigate the role of other animals in the fate of postdispersed eucalypt seeds (e.g. birds). The abundance and the scattered dispersion of areas of reduced seed predation, together with site traits, may therefore help to explain the heterogeneous recruitment patterns of E. globulus seedlings found in previous studies (Águas et al., 2017, 2014; Catry et al., 2015; Fernandes et al., 2016, 2017; Calviño-Cancela and Rubido-Bará, 2013).

\section{Conclusions}

Seeds of E. globulus were highly attractive to local fauna. Surprisingly, E. globulus and A. dealbata seeds were used in similar proportions by both vertebrates and invertebrates, despite the larger size and the elaiosome of the latter. Also, $E$. globulus seeds were more attractive to vertebrates than the native, similarly sized seeds of $C$. salviifolius. Vertebrates were the most important seed predators, particularly of E. globulus and A. dealbata seeds. Invertebrates were less important and used all seed species in similar proportions. We found spatial variation throughout the study area regarding the predominance of different types of seed predators and the rate of seed predation: predominance of vertebrates; predominance of invertebrates; negligible seed predation. Locations with negligible seed predation were abundant and 
scattered across the study area, and may help to explain the heterogeneous recruitment patterns of E. globulus seedlings found in previous studies.

Data availability. The database can be accessed online using the following link: https://goo.gl/DJ42tR.

Supplement. The supplement related to this article is available online at: https://doi.org/10.5194/we-18-67-2018-supplement.

Author contributions. ED, CF, JSS and HM designed the experiment. ED and CF collected the field data. JSS and ED analysed the data. ED prepared the manuscript with contributions from all authors. The order of authors reflects the level of contribution to the present manuscript.

Competing interests. The authors declare that they have no conflict of interest.

Acknowledgements. This research was funded by Fundação para a Ciência e a Tecnologia (FCT) as part of the "WildGum" project (FCT PTDC/AGR-FOR/2471/2012). ED was supported by a doctoral grant (PB/BD/113936/2015). We thank Filipe Carvalho for helping with the identification of the ants. We thank Santa Casa de Misericórdia de Coimbra for authorising the installation of 10 feeding stations on their property. We thank Kevin Moull for the English revision.

Edited by: Martijn Bezemer

Reviewed by: Paulo Henrique Silva and three anonymous referees

\section{References}

Abramsky, Z:: Experiments on seed predation by rodents and ants in the Israeli desert, Oecologia, 57, 328-332, https://doi.org/10.1007/BF00377176, 1983.

Águas, A., Ferreira, A., Maia, P., Fernandes, P. M., Roxo, L., Keizer, J., Silva, J. S., Rego, F. C., and Moreira, F.: Natural establishment of Eucalyptus globulus Labill. in burnt stands in Portugal, Forest Ecol. Manag., 323, 47-56, https://doi.org/10.1016/j.foreco.2014.03.012, 2014.

Águas, A., Larcombe, M. J., Matias, H., Deus, E., Potts, B. M., Rego, F. C., and Silva, J. S.: Understanding the naturalization of Eucalyptus globulus in Portugal: a comparison with Australian plantations, Eur. J. For. Res., 136, 433-446, https://doi.org/10.1007/s10342-017-1043-6, 2017.

Alba-Lynn, C. and Henk, S.: Potential for ants and vertebrate predators to shape seed-dispersal dynamics of the invasive thistles Cirsium arvense and Carduus nutans in their introduced range (North America), Plant Ecol., 210, 291-301, https://doi.org/10.1007/s11258-010-9757-2, 2010.
Andersen, A. N.: Seed removal by ants in the mallee of northwestern Victoria, in: Ant-plant interactions in Australia, edited by: Buckley, R. C., Geobotany, Dr. W. Junk Publishers, The Hague, Netherlands, 31-43, 1982.

Andersen, A. N.: How important is seed predation to recruitment in stable populations of long-lived perennials?, Oecologia, 81, 310-315, 1989.

Andersen, A. N. and Ashton, D. H.: Rates of seed removal by ants at heath and woodland sites in southeastern Australia, Aust. J. Ecol., 10, 381-390, https://doi.org/10.1111/j.14429993.1985.tb00900.x, 1985

Arnan, X., Retana, J., Rodrigo, A., and Cerdá, X.: Foraging behaviour of harvesting ants determines seed removal and dispersal, Insect. Soc., 57, 421-430, https://doi.org/10.1007/s00040010-0100-7, 2010.

Ashton, D. H.: Seed harvesting by ants in forests of Eucalyptus regnans F. Muell. in central Victoria, Aust. J. Ecol., 4, 265-277, https://doi.org/10.1111/j.1442-9993.1979.tb01218.x, 1979.

Auld, T. D.: Population dynamics of the shrub Acacia suaveolens (Sm.) Willd.: Dispersal and the dynamics of the soil seedbank, Aust. J. Ecol., 11, 235-254, https://doi.org/10.1111/j.14429993.1986.tb01395.x, 1986.

Auld, T. D. and Denham, A. J.: The role of ants and mammals in dispersal and post-dispersal seed predation of the shrubs Grevillea (Proteaceae), Plant Ecol., 144, 201-213, https://doi.org/10.1023/A:1009817132378, 1999.

Barberá, G. G., Navarro-Cano, J. A., and Castillo, V. M.: Seedling recruitment in a semi-arid steppe: the role of microsite and post-dispersal seed predation, J. Arid Environ., 67, 701-714, https://doi.org/10.1016/j.jaridenv.2006.03.019, 2006.

Bartoń, K.: R package MuMIn: Multi-Model Inference, v.1.40.4, available at: https://CRAN.R-project.org/package=MuMIn, last access: February 2018

Bas, J. M., Oliveras, J., and Gómez, C.: Myrmecochory and short-term seed fate in Rhamnus alaternus: ant species and seed characteristics, Acta Oecol., 35, 380-384, https://doi.org/10.1016/j.actao.2009.02.003, 2009.

Bastida, F. and Talavera, S.: Temporal and spatial patterns of seed dispersal in two Cistus species (Cistaceae), Ann. Bot., 89, 427434, https://doi.org/10.1093/aob/mcf065, 2002.

Bastida, F., Talavera, S., Ortiz, P. L., and Arista, M.: The interaction between Cistaceae and a highly specific seed-harvester ant in a Mediterranean scrubland, Plant Biol., 11, 46-56, https://doi.org/10.1111/j.1438-8677.2008.00066.x, 2009.

Bean, C., and Russo, M. J.: Elemental stewardship abstract for Eucalyptus globulus, The Nature Conservancy, Virginia, USA, 1986.

Becerra, P. I. and Bustamante, R. O.: The effect of herbivory on seedling survival of the invasive exotic species Pinus radiata and Eucalyptus globulus in a Mediterranean ecosystem of Central Chile, Forest Ecol. Manag., 256, 1573-1578, https://doi.org/10.1016/j.foreco.2008.04.011, 2008.

Benhamou, S.: An analysis of movements of the wood mouse Apodemus sylvaticus in its home range, Behav. Process., 22, 235250, https://doi.org/10.1016/0376-6357(91)90097-J, 1991.

Berg, R. Y.: Myrmecochorous plants in Australia and their dispersal by ants, Aust. J. Bot., 23, 475-508, https://doi.org/10.1071/BT9750475, 1975. 
Brew, C. R., O’Dowd, D. J., and Rae, I. D.: Seed dispersal by ants: behaviour-releasing compounds in elaiosomes, Oecologia, 80, 490-497, https://doi.org/10.1007/BF00380071, 1989.

Calviño-Cancela, M.: Effectiveness of eucalypt plantations as a surrogate habitat for birds, Forest Ecol. Manag., 310, 692-699, https://doi.org/10.1016/j.foreco.2013.09.014, 2013.

Calviño-Cancela, M. and Rubido-Bará, M.: Invasive potential of Eucalyptus globulus: seed dispersal, seedling recruitment and survival in habitats surrounding plantations, Forest Ecol. Manag., 305, 129-137, https://doi.org/10.1016/j.foreco.2013.05.037, 2013.

Cammell, M. E., Way, M. J., and Paiva, M. R.: Diversity and structure of ant communities associated with oak, pine, eucalyptus and arable habitats in Portugal, Insect. Soc., 43, 37-46, https://doi.org/10.1007/BF01253954, 1996.

Catry, F. X., Moreira, F., Deus, E., Silva, J. S., and Águas, A.: Assessing the extent and the environmental drivers of $\mathrm{Eu}$ calyptus globulus wildling establishment in Portugal: results from a countrywide survey, Biol. Invasions, 17, 3163-3181, https://doi.org/10.1007/s10530-015-0943-y, 2015.

Chambers, J. C. and MacMahon, J. A.: A day in the life of a seed: movements and fates of seeds and their implications for natural and managed systems, Annu. Rev. Ecol. Syst., 25, 263-292, https://doi.org/10.1146/annurev.es.25.110194.001403, 1994.

Clark, R. E. and King, J. R.: The ant, Aphaenogaster picea, benefits from plant elaiosomes when insect prey is scarce, Environ. Entomol., 41, 1405-1408, https://doi.org/10.1603/EN12131, 2012.

Colautti, R. I., Ricciardi, A., Grigorovich, I. A., and MacIsaac, H. J.: Is invasion success explained by the enemy release hypothesis?, Ecol. Lett., 7, 721-733, https://doi.org/10.1111/j.14610248.2004.00616.x, 2004.

Cremer, K. W.: How Eucalypt fruits release their seed, Aust. J. Bot., 13, 11-16, https://doi.org/10.1071/BT9650011, 1965.

Deus, E., Silva, J. S., Catry, F. X., Rocha, M., and Moreira, F.: Google Street View as an alternative method to car surveys in large-scale vegetation assessments, Environ. Monit. Assess., 188, 1-14, https://doi.org/10.1007/s10661-016-5555-1, 2016.

Deus, E., Silva, J. S., Marchante, H., Marchante, E., and Félix, C.: databaseDOI10.5194we-18-1-2018: https://goo.gl/DJ42tR, last access: April 2018.

Drake, P. L., Mendham, D. S., White, D. A., and Ogden, G. N.: A comparison of growth, photosynthetic capacity and water stress in Eucalyptus globulus coppice regrowth and seedlings during early development, Tree Physiol., 29, 663-674, https://doi.org/10.1093/treephys/tpp006, 2009.

Drake, W. E.: Ant-seed interaction in dry sclerophyll forest on North Stradbroke Island, Queensland, Aust. J. Bot., 29, 293-309, https://doi.org/10.1071/BT9810293, 1981.

Fedriani, J. M., Rey, P. J., Garrido, J. L., Guitián, J., Herrera, C. M., Medrano, M., Sánchez-Lafuente, A. M., and Cerdá, X.: Geographical variation in the potential of mice to constrain an ant-seed dispersal mutualism, Oikos, 105, 181-191, https://doi.org/10.1111/j.0030-1299.2004.12782.x, 2004.

Fenner, M. and Lee, W. G.: Lack of pre-dispersal seed predators in introduced Asteraceae in New Zealand, New Zeal. J. Ecol., 25, 95-99, 2001.

Fenner, M. and Thompson, K.: The ecology of seeds, Cambridge University Press, Cambridge, 2005.
Fernandes, P., Antunes, C., Pinho, P., Máguas, C., and Correia, O.: Natural regeneration of Pinus pinaster and Eucalyptus globulus from plantation into adjacent natural habitats, Forest Ecol. Manag., 378, 91-102, https://doi.org/10.1016/j.foreco.2016.07.027, 2016.

Fernandes, P., Máguas, C., and Correia, O.: Combined effects of climate, habitat, and disturbance on seedling establishment of $\mathrm{Pi}$ nus pinaster and Eucalyptus globulus, Plant Ecol., 218, 501-515, https://doi.org/10.1007/s11258-017-0706-1, 2017.

Gill, D. S. and Marks, P. L.: Tree and shrub seedling colonization of old fields in central New York, Ecol. Monogr., 61, 183-205, https://doi.org/10.2307/1943007, 1991.

Gorb, S. N. and Gorb, E. V.: Dropping rates of elaiosome-bearing seeds during transport by ants (Formica polyctena Foerst.): implications for distance dispersal, Acta Oecol., 20, 509-518, https://doi.org/10.1016/S1146-609X(00)86618-7, 1999.

Gosper, C. R., Stansbury, C. D., and Vivian-Smith, G.: Seed dispersal of fleshy-fruited invasive plants by birds: contributing factors and management options, Divers. Distrib., 11, 549-558, https://doi.org/10.1111/j.1366-9516.2005.00195.x, 2005.

Harris, R. J. and Standish, R. J.: Ant dispersal and predation affects the availability of seeds for old-field recolonisation in Western Australia, Royal Society of Western Australia Journal, 91, 301311, 2008.

Harwood, C.: New introductions - doing it right, in: Developing a eucalypt resource: learning from Australia and elsewhere, edited by: Walker, J., Wood Technology Research Centre, Christchurch, New Zealand, 43-54, 2011.

Holmes, P. M.: Dispersal and predation of alien Acacia seeds: effects of season and invading stand density, S. Afr. J. Bot., 56, 428-434, 1990.

Hothorn, T., Bretz, F., and Westfall, P.: Simultaneous inference in general parametric models, Biometrical J., 50, 346-363, https://doi.org/10.1002/bimj.200810425, 2008.

Hughes, L., Westoby, M., and Jurado, E.: Convergence of elaiosomes and insect prey: evidence from ant foraging behaviour and fatty acid composition Funct. Ecol., 8, 358-365, https://doi.org/10.2307/2389829, 1994.

Hulme, P. E.: Post-dispersal seed predation in grassland: its magnitude and sources of variation, J. Ecol., 82, 645-652, https://doi.org/10.2307/2261271, 1994.

Hulme, P. E.: Post-dispersal seed predation and the establishment of vertebrate dispersed plants in Mediterranean scrublands, Oecologia, 111, 91-98, 1997.

Hulme, P. E.: Post-dispersal seed predation: consequences for plant demography and evolution, Perspect. Plant Ecol., 1, 32-46, https://doi.org/10.1078/1433-8319-00050, 1998.

Human, K. G. and Gordon, D. M.: Exploitation and interference competition between the invasive Argentine ant, Linepithema humile, and native ant species, Oecologia, 105, 405-412, https://doi.org/10.1007/bf00328744, 1996.

IPMA: Climatological normals 1981-2010 (provisional) - Coimbra, available at: https://www.ipma.pt/pt/oclima/normais.clima/ 1981-2010/006/ (last access: February 2018), 2014.

Jacobs, M. R.: Eucalypts for planting, Food and Agriculture Organization of the United Nations, Rome, 1979.

Jamon, M.: An analysis of trail-following behaviour in the wood mouse, Apodemus sylvaticus, Anim. Behav., 47, 1127-1134, https://doi.org/10.1006/anbe.1994.1151, 1994. 
Janzen, D. H.: Seed-eaters versus seed size, number, toxicity and dispersal, Evolution, 23, 1-27, https://doi.org/10.1111/j.15585646.1969.tb03489.x, 1969.

Jordan, G. J., Borralho, N. M. G., Tilyard, P., and Potts, B. M.: Identification of races in Eucalyptus globulus spp globulus based on growth traits in Tasmania and geographic distribution, Silvae Genet., 43, 292-298, 1994.

Keane, R. M. and Crawley, M. J.: Exotic plant invasions and the enemy release hypothesis, Trends Ecol. Evol., 17, 164-170, https://doi.org/10.1016/S0169-5347(02)02499-0, 2002.

Levey, D. J. and Byrne, M. M.: Complex ant-plant interactions: rain-forest ants as secondary dispersers and post-dispersal seed predators, Ecology, 74, 1802-1812, https://doi.org/10.2307/1939938, 1993.

López, M., Humara, J. M., Casares, A., and Majada, J.: The effect of temperature and water stress on laboratory germination of $E u$ calyptus globulus Labill. seeds of different sizes, Ann. For. Sci., 57, 245-250, https://doi.org/10.1051/forest:2000115, 2000.

Lorenzo, P., González, L., and Reigosa, M. J.: The genus Acacia as invader: the characteristic case of Acacia dealbata Link in Europe, Ann. For. Sci., 67, p. 101, https://doi.org/10.1051/forest/2009082, 2010.

Manson, R. H. and Stiles, E. W.: Links between microhabitat preferences and seed predation by small mammals in old fields, Oikos, 82, 37-50, https://doi.org/10.2307/3546915, 1998.

Marchante, H., Freitas, H., and Hoffmann, J. H.: Seed ecology of an invasive alien species, Acacia Longifolia (Fabaceae), in Portuguese dune ecosystems, Am. J. Bot., 97, 1780-1790, https://doi.org/10.3732/ajb.1000091, 2010.

Meiss, H., Lagadec, L. L., Munier-Jolain, N., Waldhardt, R., and Petit, S.: Weed seed predation increases with vegetation cover in perennial forage crops, Agr. Ecosyst. Environ., 138, 10-16, https://doi.org/10.1016/j.agee.2010.03.009, 2010.

Milewski, A. V. and Bond, W. J.: Convergence of myrmecochory in mediterranean Australia and South Africa, in: Ant-seed interaction in Australia, edited by: Buckley, R. C., Dr. W. Junk Publishers, The Hague, 89-98, 1982.

Mitchell, C. E. and Power, A. G.: Release of invasive plants from fungal and viral pathogens, Nature, 421, 625-627, 2003.

Montesinos, D., Castro, S., and Rodríguez-Echeverría, S.: Invasive acacias experience higher ant seed removal rates at the invasion edges, Web Ecol., 12, 33-37, https://doi.org/10.5194/we-12-332012, 2012.

Moreira, B., Tavsanoglu, Ç., and Pausas, J. G.: Local versus regional intraspecific variability in regeneration traits, Oecologia, 168, 671-677, https://doi.org/10.1007/s00442-011-2127-5, 2012.

Morton, S. R.: Granivory in arid regions: comparison of Australia with North and South America, Ecology, 66, 1859-1866, https://doi.org/10.2307/2937381, 1985.

Myster, R. W. and Pickett, S. T. A.: Effects of litter, distance, density and vegetation patch type on postdispersal tree seed predation in old fields, Oikos, 66, 381-388, https://doi.org/10.2307/3544932, 1993.

Nakagawa, S. and Schielzeth, H.: A general and simple method for obtaining $R^{2}$ from generalized linear mixed-effects models, Methods Ecol. Evol., 4, 133-142, https://doi.org/10.1111/j.2041210x.2012.00261.x, 2013.
O’Dowd, D. J. and Gill, A. M.: Predator satiation and site alteration following fire: mass reproduction of alpine ash (Eucalyptus delegatensis) in Southeastern Australia, Ecology, 65, 1052-1066, https://doi.org/10.2307/1938313, 1984.

Ordóñez, J. L. and Retana, J.: Early reduction of post-fire recruitment of Pinus nigra by post-dispersal seed predation in different time-since-fire habitats, Ecography, 27, 449-458, 2004.

Potts, B. M.: Genetic improvement of eucalypts, in: Encyclopedia of forest science, edited by: Burley, J., Evans, J., and Youngquist, J. A., Elsevier Science, Oxford, 1480-1490, 2004.

R Core Team: R: a language and environment for statistical computing, available at: http://www.R-project.org (last access: February 2018), 2017.

Rejmánek, M. and Richardson, D. M.: Eucalypts, in: Encyclopedia of Biological Invasions, edited by: Simberloff, D. and Rejmánek, M., University of California Press, California, USA, 203-209, 2011.

Rejmánek, M. and Richardson, D. M.: Trees and shrubs as invasive alien species - 2013 update of the global database, Divers. Distrib., 19, 1093-1094, https://doi.org/10.1111/ddi.12075, 2013.

Rejmánek, M., Richardson, D. M., Higgins, S. I., Pitcairn, M. J., and Grotkopp, E.: Ecology of invasive plants - state of the art, in: Invasive alien species: a new synthesis, edited by: Mooney, H. A., Mack, R. N., McNeely, J. A., Neville, L., Schei, P. J., and Waage, J., Island Press, Washington, D.C., USA, 104-161, 2005.

Retana, J., Picó, F. X., and Rodrigo, A.: Dual role of harvesting ants as seed predators and dispersers of a nonmyrmechorous Mediterranean perennial herb, Oikos, 105, 377385, https://doi.org/10.1111/j.0030-1299.2004.12854.x, 2004.

Richardson, D. M., Allsopp, N., D’Antonio, C. M., Milton, S. J., and Rejmánek, M.: Plant invasions - the role of mutualisms, Biol. Rev., 75, 65-93, https://doi.org/10.1111/j.1469185X.1999.tb00041.x, 2000.

Rouget, M. and Richardson, D. M.: Inferring process from pattern in plant invasions: a semimechanistic model incorporating propagule pressure and environmental factors, Am. Nat., 162, 713-724, https://doi.org/10.1086/379204, 2003.

Santos, P., Matias, H., Deus, E., Águas, A., and Silva, J. S.: Fire effects on capsules and encapsulated seeds from $\mathrm{Eu}$ calyptus globulus in Portugal, Plant Ecol., 216, 1611-1621, https://doi.org/10.1007/s11258-015-0544-y, 2015.

Silva, J. S., dos Santos, P., Sério, A., and Gomes, F.: Effects of heat on dehiscence and germination in Eucalyptus globulus Labill., Int. J. Wildland Fire, 25, 478-483, https://doi.org/10.1071/WF15078, 2016.

Sivy, K. J., Ostoja, S. M., Schupp, E. W., and Durham, S.: Effects of rodent species, seed species, and predator cues on seed fate, Acta Oecol., 37, 321-328, https://doi.org/10.1016/j.actao.2011.03.004, 2011.

Suitor, S.: Factors affecting capsule and seed set in Eucalyptus globulus seed orchards, PhD thesis, School of Agricultural Science, University of Tasmania, Tasmania, 2008.

Thanos, C. A. and Georghiou, K.: Ecophysiology of fire-stimulated seed germination in Cistus incanus ssp. creticus (L.) Heywood and C. salvifolius L., Plant Cell Environ., 11, 841-849, https://doi.org/10.1111/j.1365-3040.1988.tb01910.x, 1988.

Vander Wall, S. B.: Removal of wind-dispersed pine seeds by ground-foraging vertebrates, Oikos, 69, 125-132, https://doi.org/10.2307/3545292, 1994. 
Venables, W. N. and Ripley, B. D.: Modern applied statistics with S, in: Statistics and Computing, edited by: Härdle, W. K., Springer, New York, USA, 2002.

Wandrag, E. M., Sheppard, A., Duncan, R. P., and Hulme, P. E.: Mutualism vs. antagonism in introduced and native ranges: can seed dispersal and predation determine Acacia invasion success?, Perspect. Plant Ecol., 15, 171-179, https://doi.org/10.1016/j.ppees.2013.03.002, 2013.

Wellington, A. B. and Noble, I. R.: Seed dynamics and factors limiting recruitment of the mallee Eucalyptus incrassata in semi-arid, South-Eastern Australia, J. Ecol., 73, 657-666, https://doi.org/10.2307/2260502, 1985.
Whelan, C. J., Willson, M. F., Tuma, C. A., and Souza-Pinto, I.: Spatial and temporal patterns of postdispersal seed predation, Can. J. Botany, 69, 428-436, https://doi.org/10.1139/b91-059, 1991.

Wolfe, L. M.: Why alien invaders succeed: support for the escape-from-enemy hypothesis, Am. Nat., 160, 705-711, https://doi.org/10.1086/343872, 2002.

Zuur, A., Ieno, E. N., Walker, N., Saveliev, A. A., and Smith, G. M.: Mixed effects models and extensions in ecology with $\mathrm{R}$, in: Statistics for biology and health, edited by: Gail, M., Samet, J. M., Tsiatis, A., and Wong, W., Springer, New York, 2009. 